\title{
Evaluation of Human Skin-Derived Stem Cell Characteristics After Non-Invasive Quantum Dot Labeling
}

\author{
Heiko Benzin ${ }^{a}$ Sandra Schumanna,b Anja Richter ${ }^{a} \quad$ Janina Kier ${ }^{a} \quad$ Charli Kruse ${ }^{a, b}$ \\ Anna Emilia Matthiessen ${ }^{a, b}$ \\ aFraunhofer Research Institution for Marine Biotechnology and Cell Technology, Lübeck, Germany, \\ 'Institute for Medical and Marine Biotechnology, University of Lübeck, Lübeck, Germany
}

\section{Key Words}

Adult stem cells $•$ Epidermal cells $•$ Nanoparticles $•$ Quantum dots $\bullet$ Cell tracking

\begin{abstract}
Background/Aims: The use of skin-derived stem cells and stem cells of other origins in regenerative medicine requires knowledge of stem cell fate after transplantation. In order to achieve non-invasive long-term imaging and tracking of transplanted stem cells in preclinical studies, a non-toxic, efficient labeling technique that does not alter stem cell characteristics must be used. Our aim was to investigate a method for such a long-term cell-compatible cell tracer using nanoparticles. Methods: Nanotechnology, in particular the use of quantum dots (QDs), offers great advantages for this crucial requirement. In this study, we used nanocrystals coated with a specific target peptide that enables delivery into the cytoplasm of cells, resulting in an intense and stable fluorescent labeling. We analyzed the influence of biocompatible $\mathrm{CdSe} / \mathrm{ZnS}-\mathrm{QDs}$ on epidermal stem cells (EpiSCs) isolated from adult human skin. Thereby we analyzed on QD loading, cell proliferation including QD transfer to descendent daughter cells as well as the influence on the differentiation potential of stem cells after QD labeling. Results: FACS analysis revealed a dose-dependent QD incorporation into the cells. Thereby, a high initial concentration of nanocrystals resulted in a more stable long-term labeling. QD labeled cells showed normal viability and unchanged ability to proliferate. The spread of QDs during cell division was monitored by time lapse microscopy and two modes of QD distribution could be observed. Daughter cells either received an equal amount of QDs after cell division, which led to a homogenously faded fluorescence signal, or there was an uneven transmission of QDs, which led to unchanged labeling of one cell and a complete loss of the fluorescence signal of the other cell. The spontaneous differentiation potential remained unaffected after QD exposure, since skin-derived EpiSCs showed an unchanged protein and gene expression profile. Conclusion: In summary, we can conclude that QDs offer a successful, non-invasive and efficient labeling technique for EpiSCs, which makes their in vitro and in vivo use in skin
\end{abstract}




\section{Cellular Physiology Cell Physiol Biochem 2021;55:387-399 \\ \begin{tabular}{ll|l} 
DOl: $10.33594 / 000000391$ & $\begin{array}{l}\text { O } 2021 \text { The Author(s). Published by } \\
\text { Cell Physiol Biochem Press GmbH\&Co. }\end{array}$
\end{tabular} \\ Benzin et al.: Q-Dot Labeling of Skin-Derived Stem Cells}

regeneration and wound healing models traceable. Nevertheless, the uneven transmission of QDs should not be disregarded and the extent and frequency should be investigated in further studies.

\section{Introduction}

With recent advances in regenerative medicine and cell-based therapies, there is a strong need for new and improved labeling techniques of cells used either in vitro or in vivo. The main goal is long-term non-invasive imaging and tracking of transplanted cells to monitor their survival, migration, differentiation and regenerative effects [1].

Nanotechnology, especially the use of QDs, offers major advantages for highly sensitive tracking of stem cells. In contrast to organic dyes or fluorescent proteins, QDs are superior due to their photostability and sustained fluorescence intensity [2, 3]. Among various QD types and different coatings [4-6], commercially available QDs for cell labeling discussed here are made from a cadmium selenide core that is surrounded by a zinc sulfide shell. Using a custom targeting peptide $\mathrm{CdSe} / \mathrm{ZnS}$ nanocrystals can easy be delivered into the cytoplasm of living cells $[7,8]$.

In a previous study, we reported no adverse effects of CdSe/ZnS QD labeling on the differentiation potential of adult stem cells isolated from rat pancreas [9]. Similar observations for other stem cell types such as embryonic stem cells, induced pluripotent stem cells or mesenchymal ones have recently been published [10-12]. Intriguingly, others have noted changes in the differentiation profile of stem cells after labeling with nanoparticles such as the inhibition of osteogenesis with QD labeled bone marrow mesenchymal stem cells [1315]. In view of these possible effects of QDs on different cell types, the analysis of an influence for each individual cell type is inevitable.

The core function of human skin adult epidermal stem cells (EpiSCs) is lifelong selfrenewal. As a highly proliferative cell population, they are located on the basement membrane between the epidermis and the dermis $[16,17]$ and pursue their way of terminal differentiation by leaving their niche and migrating vertically to replace damaged or dead cells and thus ensure tissue homeostasis $[16,18]$.

Because of their promising potential for skin regeneration, EpiSCs have become an attractive tool especially for skin wound healing. The current gold standards of autologous skin grafts or xenogeneic swine-derived grafts are often limited in their graft size combined with functional and aesthetic issues [19]. The aim of matrix-based cell therapies is to ensure complete, scar-free regeneration including skin appendages such as glands and hair follicles, as well as functional vascularization [20,21]. It is therefore of major importance to closely monitor the application of cells in human wound healing with regard to their distribution, migration, proliferation and differentiation in order to prevent adverse cell functions and minimize the risk for the patients being treated [22].

Looking for a suitable labeling method for further in vivo experiments, we here describe the effects of CdSe/ZnS-QD labeling on human EpiSCs in vitro for the first time in order to rule out a negative effect on the behavior of the cells. 


\section{Cellular Physiology Cell Physiol Biochem 2021;55:387-399

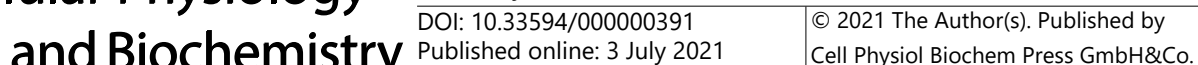 \\ Benzin et al.: Q-Dot Labeling of Skin-Derived Stem Cells}

\section{Materials and Methods}

\section{Human epidermal stem cells}

Human epidermal stem cells (EpiSCs) were isolated according to their ability to adhere to collagen type IV rapidly described by Kim et al. [23].

EpiSCs used in this study were isolated from human abdominal and groin skin biopsies obtained from plastic surgery intervention. Male and female donors were aged between 28 and 58 years to consider patients variability. In brief, the tissue was minced into small pieces and incubated overnight in dispase $(2,0$ $\mathrm{U} / \mathrm{ml}$, Roche, Germany) to detach the epidermis from the dermis. The epidermis was further treated with trypsin ( $0.05 \%$ in $1 \mathrm{x}$ DPBS, PAA, Austria) for $10 \mathrm{~min}$ interrupted by resuspension through a $1000 \mu \mathrm{l}$ pipette tip. The reaction was blocked with $10 \%$ FCS in DPBS (1x, Gibco, Germany) followed by centrifugation for $5 \mathrm{~min}$ and $180 \mathrm{~g}$. Cells were seeded on collagen type IV coated culture dishes (BD Biosciences, USA) in EpiLife $®$ defined Growth Medium with EDGS (both Gibco, Germany) and $0.6 \%$ antibiotic-antimycotic mix (100 x, Gibco, Germany). After incubation for $7 \mathrm{~min}$ at $37^{\circ} \mathrm{C}$ free floating cells were removed, selecting fast adherent cells for further cultivation. Culture medium was changed every 3-4 days and subcultivation took place at $90 \%$ confluency. In this study, cells were analyzed in passage 3.

\section{Quantum dot labeling}

Following the manufacturer's instruction Qdot ${ }^{\circledR}$ Nanocrystals Qtracker ${ }^{\circledR} 605$ (QD; Molecular Probes ${ }^{\circledR}$, Germany) were used to label human epidermal stem cells. The core of these nanocrystals is made up of cadmium selenide (CdSe) surrounded by a zinc sulfide $(\mathrm{ZnS})$ shell. The excitation of these nanocrystals ranges from 405 to $565 \mathrm{~nm}$ in contrast to their sharp emission at $605 \mathrm{~nm}$. In addition to the recommended concentration $(10 \mathrm{nM})$ a lower $(5 \mathrm{nM})$ and a higher concentration $(20 \mathrm{nM})$ were applied. The labeling kit was composed of nanocrystals and the corresponding carrier, a custom targeting peptide [24, 25], which enabled the uptake by cells. After incubation for $1 \mathrm{~h}$ the cells were washed twice with culture medium and were further cultivated before experiments took place.

\section{FACS analysis}

To quantify the amount of labeled cells $1 \mathrm{~h}, 24 \mathrm{~h}, 48 \mathrm{~h}$ and $96 \mathrm{~h}$ after QD labeling, fluorescence activated cell sorting (FACS Calibur, BD Biosciences, USA) was performed on EpiSCs labeled with different QD concentrations ( $5 \mathrm{nM}, 10 \mathrm{nM}$ and $20 \mathrm{nM}$ ). Therefore, EpiSCs at passage 3 isolated from 3 different donors were seeded in cell culture dishes (diameter: $60 \mathrm{~mm}$ ) at a density of 8400 cells $/ \mathrm{cm}^{2}$ and labeled with QDs $24 \mathrm{~h}$ later. For FACS analysis EpiSCs were harvested and resuspended in PBS with $1 \%$ FCS. Furthermore, an unlabeled control was analyzed at every time point.

\section{Time lapse microscopy}

EpiSCs at passage 3 from 3 different donors were seeded into 6-well-culture plates at a density of 8800 cells $/ \mathrm{cm}^{2}$ and labeled after $24 \mathrm{~h}$ of cultivation with $10 \mathrm{nM}$ QDs and $20 \mathrm{nM}$ QDs respectively. Using a time lapse microscope (Axiovert $200 \mathrm{M}$, Zeiss, Germany) combined with an incubator $\left(37^{\circ} \mathrm{C}, 5 \% \mathrm{CO}_{2}\right)$ labeled cells were monitored over a period of 5 days. Images were recorded every $15 \mathrm{~min}$ and finally composed to a movie. Unlabeled cells were analyzed as a negative control.

\section{Growth characteristics}

To analyze the impact of QDs on proliferation of human EpiSCs the growth of labeled and unlabeled cells was observed over a period of 10 days. Cells were seeded in triplicates into 6-well culture plates in a density of 4400 cells $/ \mathrm{cm}^{2}$. One day after seeding, cells were labeled with $10 \mathrm{nM}$ QDs. Unlabeled cells were kept in culture as a control. During the following 10 days the cells were harvested and counted with NucleoCounter (Chemometec, Denmark) at several time points (1, 2, 4, 6, 8 and 10 days). This experiment was done with cells from 3 different patients.

Gene expression analysis

EpiSCs of 3 different donors were seeded in cell culture dishes (diameter: $100 \mathrm{~mm}$ ) in a density of 1200 cells $/ \mathrm{cm}^{2}$ pre-cultured for 5 days. One of each dish was incubated with $10 \mathrm{nM}$ quantum dots and further cultivation of labeled and unlabeled cells took place for $48 \mathrm{~h}$ before total RNA was isolated. This 


\section{Cellular Physiology Cell Physiol Biochem 2021;55:387-399 \\ \begin{tabular}{ll|l} 
DOl: 10.33594/000000391 & $\begin{array}{l}\text { O } 2021 \text { The Author(s). Published by } \\
\text { Cell Physiol Biochem Press GmbH\&Co. KG }\end{array}$ \\
\cline { 2 - 3 }
\end{tabular} \\ Benzin et al.: Q-Dot Labeling of Skin-Derived Stem Cells}

was performed using the RNA Plus Mini kit and the QIAcube for automated RNA isolation (both Qiagen, Germany) according to the manufacturer's protocols. This procedure included a genomic DNA elimination step. RNA concentration was determined by a nanodrop spectrophotometer (PEQLAB Biotechnology, Germany) and cDNA was synthesized from $500 \mathrm{ng}$ template RNA using the QuantiTect reverse transcription kit (Qiagen, Germany) which included a further genomic DNA digestion step. Real-time polymerase chain reaction (PCR) was carried out in with $1 \mu \mathrm{l} \mathrm{cDNA}$ in a $25 \mu \mathrm{l}$ reaction volume using the QuantiFast SYBR Green PCR kit and human specific QuantiTect primers for: $\beta$-actin (149 bp), integrin $\alpha 6$ (142 bp), involucrin (120 bp), keratin 7 (103 bp), keratin 10 (91 bp), keratin 14 (76 bp), ki67 (86 bp), laminin $\alpha 3$ (107 bp), nidogen (123 bp) and p63 (130 bp) (kit and all primer from Qiagen, Germany). The gene expression level of both, labeled and untreated cells, was determined using the housekeeping gene beta-actin as a reference.

\section{Immunocytochemical analysis}

EpiSCs of 3 different donors were seeded on 2-well-chamberslides $\left(3750\right.$ cells $/ \mathrm{cm}^{2}$; BD Biosciences, USA) and pre-cultured for 5 days. Half of the wells were incubated with $10 \mathrm{nM}$ QDs and further cultivation of labeled and unlabeled cells took place for $48 \mathrm{~h}$. Afterwards the cells were washed with PBS and fixed with $4 \%$ paraformaldehyde (PFA, Merck, Germany) for $15 \mathrm{~min}$ at room temperature. Next, cells were rinsed three times with PBS and incubated with $0.1 \%$ Tween 20 (VWR International BDH Prolabo, Germany) for 5 min. Subsequently, samples were blocked with $1.7 \%$ normal goat serum (Vector Laboratories, USA) for the minimum of 20 min at RT. Primary antibodies against: Integrin $\alpha 6$ (1:250, rat monoclonal, Santa Cruz, USA), Keratin 7 (1:500, rabbit polyclonal, Abcam, United Kingdom), Keratin 10 (1:200, mouse monoclonal, Millipore, USA), Keratin 14 (1:500, mouse monoclonal, Santa Cruz, USA), Ki67 (1:500, rabbit polyclonal, Abcam, United Kingdom), Laminin 5 (1:500, mouse monoclonal, Santa Cruz, USA), p63 (1:250, mouse monoclonal, Santa Cruz, USA) diluted in TBS-T (tris-buffered saline-triton X: $150 \mathrm{mM} \mathrm{NaCl}$ (Merck, Germany), $10 \mathrm{mM}$ Tris (pH 8.8; biomol, Germany), $0.05 \%$ TritonX (Bio-Rad, USA)) containing $0.1 \%$ bovine serum albumin (PAA Laboratories, Austria) were incubated in a humid chamber for $1 \mathrm{~h}$ at $37^{\circ} \mathrm{C}$. After rinsing three times with PBS samples were incubated under the same conditions with the appropriate secondary antibody: FITCconjugated anti-rat IgG (1:100), FITC-conjugated anti-rabbit IgG (1:200), FITC-conjugated anti-mouse IgG (1:200, all Jackson ImmunoResearch Europe, United Kingdom) diluted in PBS. Subsequently a nucleus staining with DAPI (1:1000 in PBS; Roche, Switzerland) took place for 5 min followed by washing three times in PBS. Finally, the samples were mounted in Vectashield $®$ mounting medium (Vector Laboratories, USA) and analyzed by fluorescence microscopy Axio Observer Z.1 (Zeiss, Germany). Quantification of marker expression was done by counting representative regions of interest containing from 1900 up to 4400 cells per marker and thereby identifying positive cells.

\section{Results}

\section{QD labeling of epidermal stem cells}

In addition to the manufacturer's recommendation of $10 \mathrm{nM}$, a lower ( $5 \mathrm{nM})$ and a higher concentration (20 nM) were applied to the cells in order to determine the appropriate QD concentration for labeling EpiSCs. Microscopic analysis of EpiSCs showed a weak signal using $5 \mathrm{nM}$ QDs, while $10 \mathrm{nM}$ and $20 \mathrm{nM}$ QDs resulted in strong fluorescent labeling of the cells with no distinguishable difference between the two concentrations (Fig. 1). FACS analysis, which allowed to monitor the fluorescence signal per cell, provided a deeper insight into QD loading of the cells. Thereby, the highest initial signal could be shown in cells labeled with $20 \mathrm{nM}$ QDs. Furthermore, in the $20 \mathrm{nM}$ approach, the fluorescence signal decreased only within the first $24 \mathrm{~h}$ of cultivation and remained stable thereafter, while in the $5 \mathrm{nM}$ and the $10 \mathrm{nM}$ approaches the signal decreased continuously within the monitored period of $72 \mathrm{~h}$ (Fig. 2A). In addition to the analysis of the fluorescence intensity, positively labeled cells were quantified over a cultivation period of $72 \mathrm{~h}$. The use of $20 \mathrm{nM}$ QDs resulted in an almost unchanged number of positive cells over the entire period (99.0\%; Fig. 2B), while a slight decrease could be observed using $10 \mathrm{nM}$ QDs (92.6\%) and a more pronounced decrease using $5 \mathrm{nM}$ QDs (74.6\%). 
Fig. 1. Incorporation of QDs into EpiSCs. Cells labeled with different QD concentrations (0 $\mathrm{nM}, 5 \mathrm{nM}, 10 \mathrm{nM}$ and $20 \mathrm{nM}$ ) were monitored over a period of $72 \mathrm{~h}$ by using a combination of phase contrast and fluorescence microscopy; scale bars: $50 \mu \mathrm{m}$.

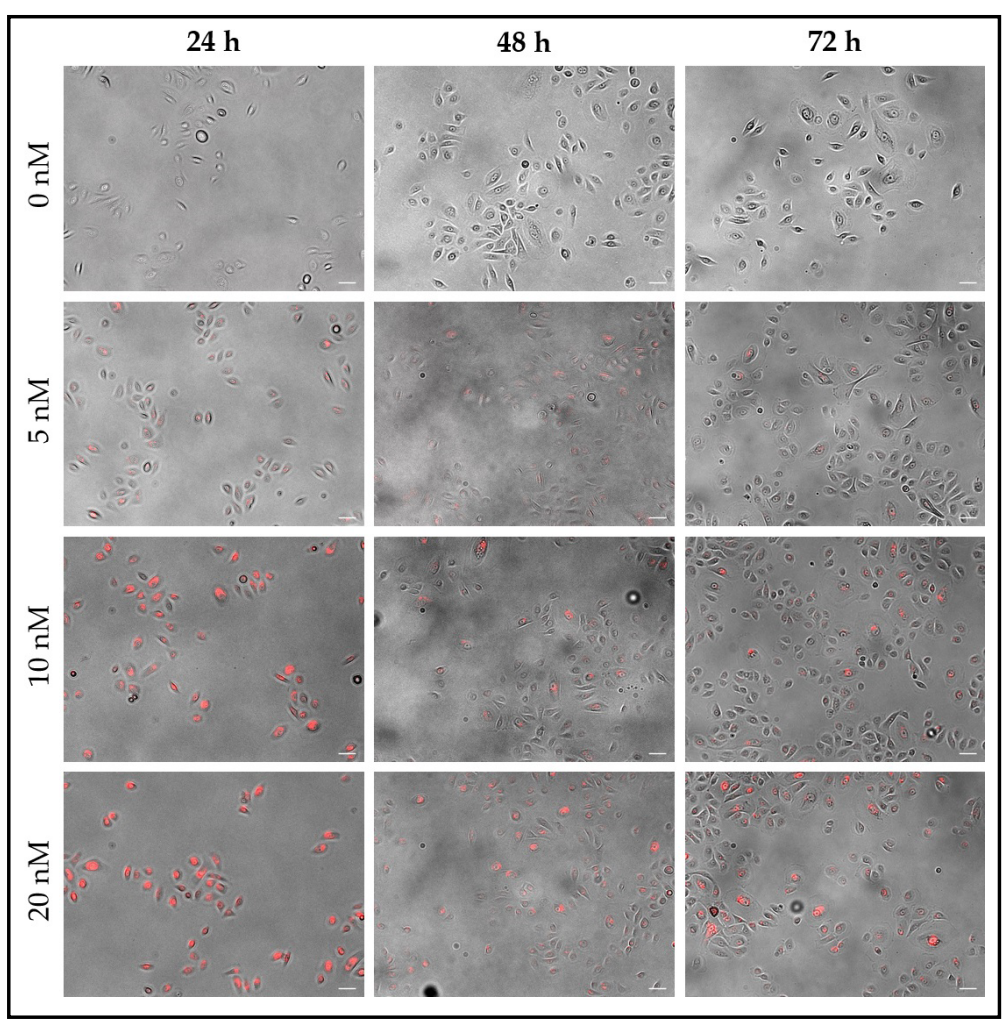

A
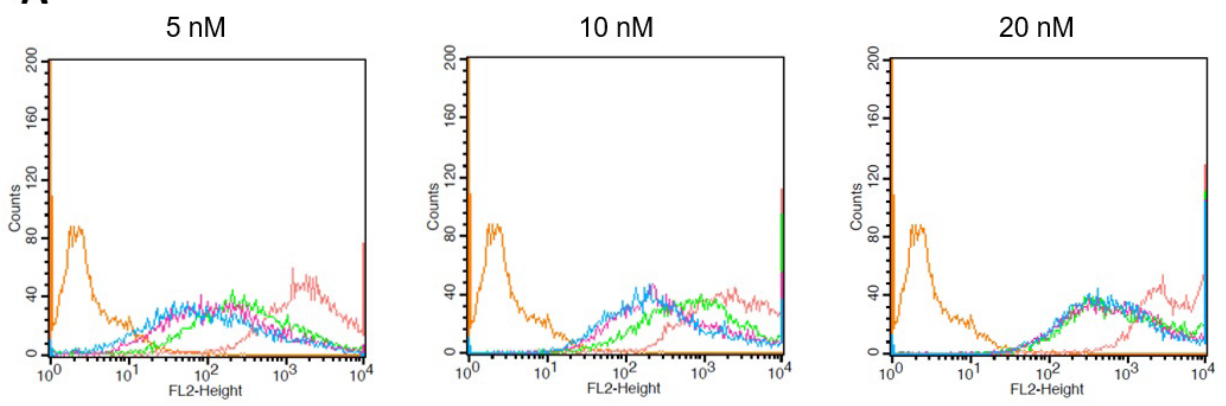

control

$1 \mathrm{~h}$

$24 \mathrm{~h}$

$48 \mathrm{~h}$

$72 \mathrm{~h}$

B

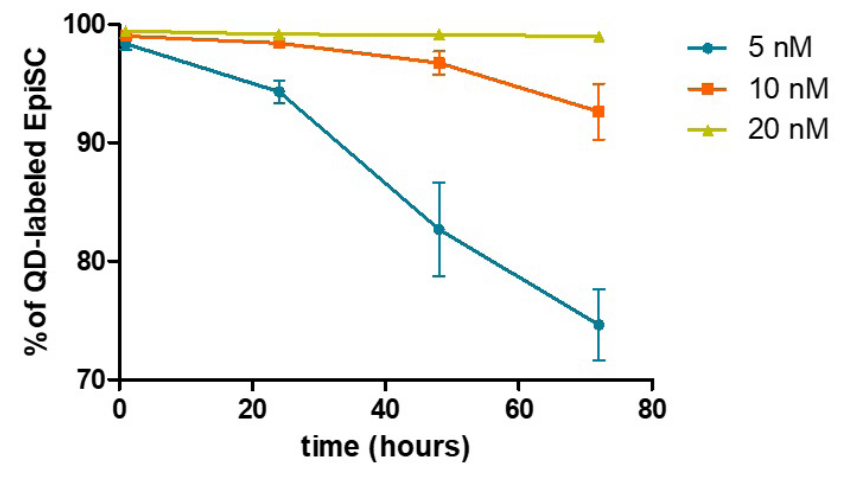

Fig. 2. FACS analysis of EpiSC labeled with different QD concentrations. A: The fluorescence within cells labeled with $5 \mathrm{nM}, 10 \mathrm{nM}$ and $20 \mathrm{nM}$ QDs was analyzed after $1 \mathrm{~h}, 24 \mathrm{~h}, 48 \mathrm{~h}$ and $72 \mathrm{~h}$, here shown for cells from one patient exemplarily. B: Decrease of QD positive cells after labeling with $5 \mathrm{nM}, 10 \mathrm{nM}$ and $20 \mathrm{nM}$ QDs was monitored over a period of $72 \mathrm{~h}$. Data is shown as mean \pm SE. $(n=3)$. 


\section{Cellular Physiology and Biochemistry

Time lapse analysis of $Q D$ distribution during cell division

To investigate how QDs were passed on to daughter cells during cell division, proliferating EpiSCs were imaged after labeling with QDs over a period of 4 days by time lapse microscopy (Fig. 3). Thereby, a thinning of the labeling could be observed. Obviously QD transfer took place in two different ways whereby the distribution of nanoparticles during cell division had an impact on the labeling of daughter cells (Fig. 4). An unsymmetrical distribution of nanoparticles within the cell led to an uneven transmission of QDs after cell division. This resulted in a daughter cell with a stable fluorescent signal on the one hand and a completely unlabeled daughter cell on the other hand. Following a homogeneous distribution of nanoparticles in the cell an equal spread of QDs during cell division was detectable, which led to two daughter cells with a similar amount of QDs. This uniform distribution was always accompanied by a thinning of the QD concentration leading to a constant fading of the fluorescence signal with each cell division.

\section{Proliferation characteristics of QD labeled EpiSCs}

In order to study the influence of QDs on the proliferation and their long-term labeling potential of human epidermal stem cells in vitro, a growth curve with cells from three patients each was recorded over a period of 10 days with QD labeled and unlabeled cells (Fig. 5). In both conditions a lag phase was followed by a log phase, which then resulted in a stationary phase. No difference in the proliferation capability could be observed, when a labeling concentration of $10 \mathrm{nM}$ was used.

\section{Impact of QDs on the expression of EpiSCs characteristic proteins}

Human epidermal stem cells exhibit a very distinct protein expression profile in vitro. In order to rule out adverse effects of QD labeling on epidermal stem cell characteristics, the expression of specific marker proteins was investigated at transcriptional and translational level, performing qRT-PCR and immunocytochemical staining.

Fig. 3. Time lapse microscopy of QD labeled EpiSCs. The distribution of QDs and the intensity of labeling were monitored over a cultivation time of 4 days by using a combination of phase contrast and fluorescence microscopy; scale bars: $50 \mu \mathrm{m}$.
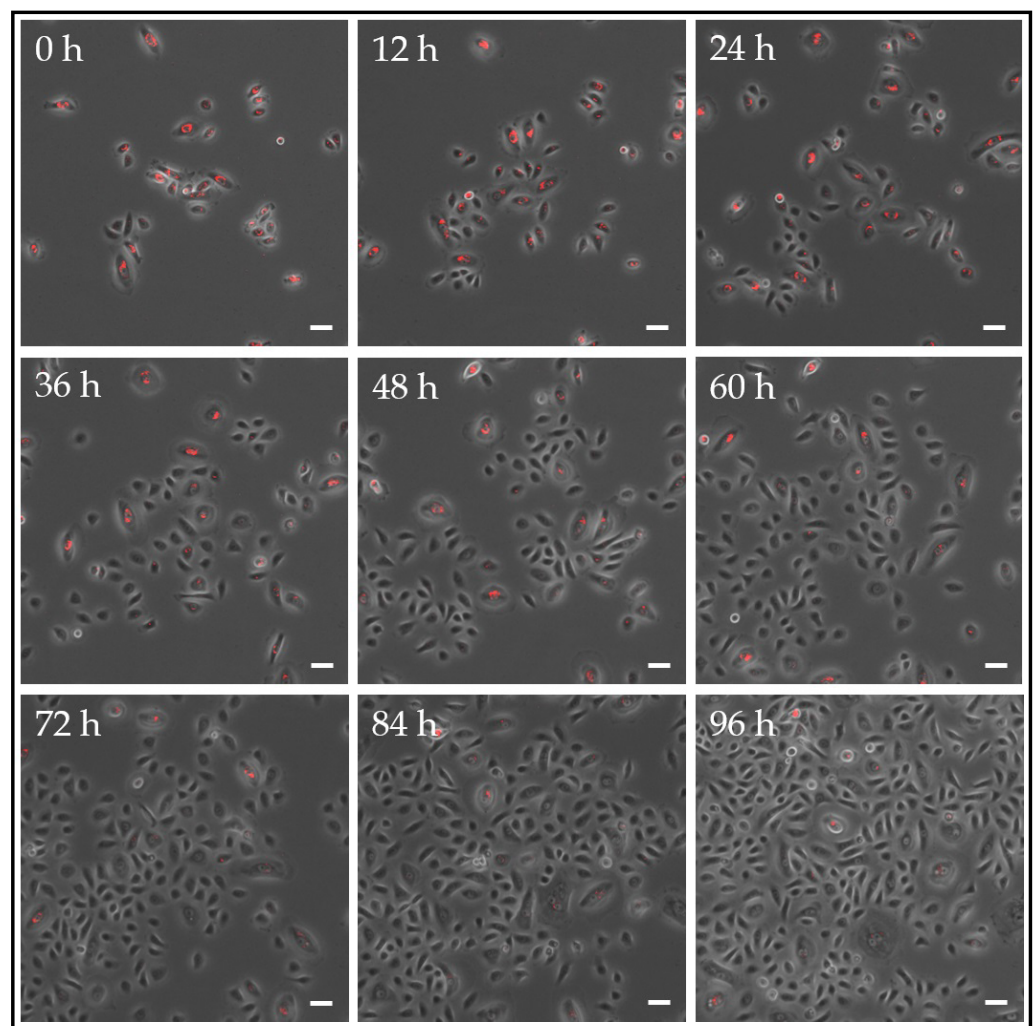
The expression level of analyzed genes remained the same after QD labeling of EpiSCs (Fig. 6). Transcripts for the epidermal stem cell marker p63 as well as for epidermal specific keratins like K7, K10, K14 and specific extracellular proteins like integrin $\alpha 6$, involucrin and laminin 3 were still at the same level after labeling with QDs and cultivation for the period of $48 \mathrm{~h}$.

Fig. 4. Passing on of QDs during cell division. Time lapse microscopy combining phase contrast and flurorescence over a period of $2 \mathrm{~h}$ revealed an asymmetrical distribution of QDs during cell division resulting in an unequal passing on of QDs (yellow arrow head) and a symmetrical distribution of QDs leading to an equal passing on of QDs (blue arrow head); scale bars: $50 \mu \mathrm{m}$.

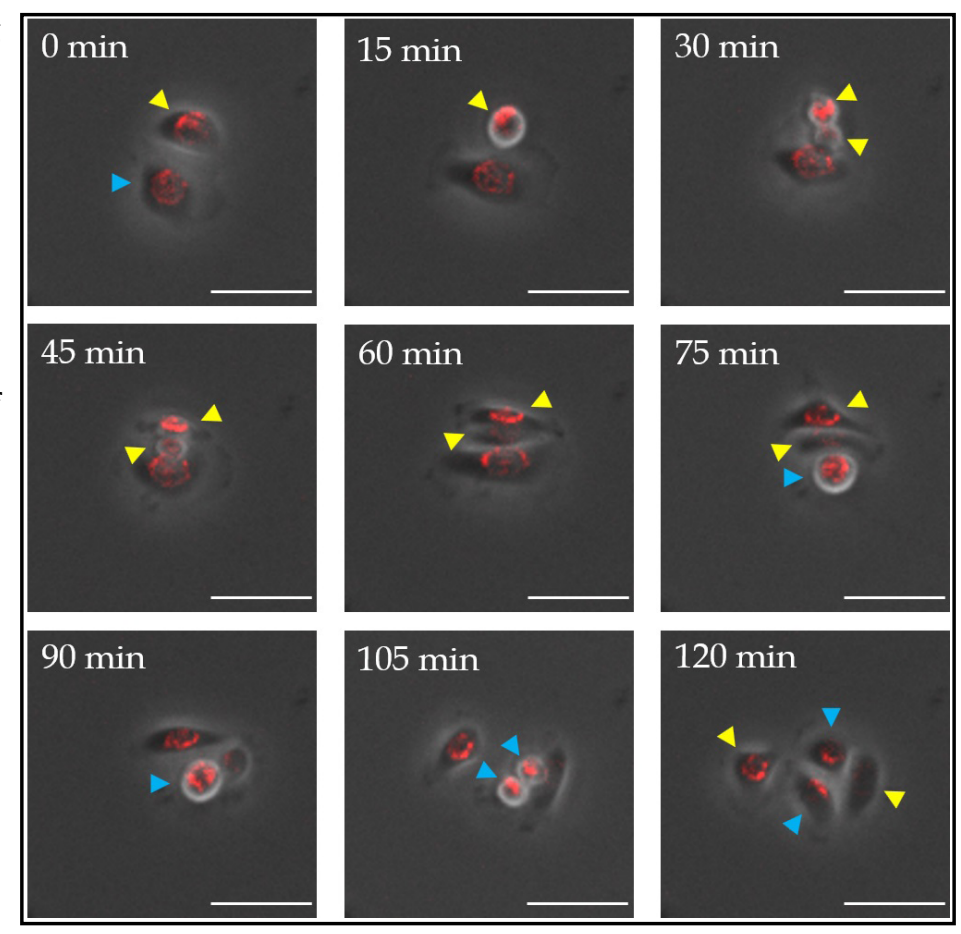

Fig. 5. Growth curve of $Q D$ labeled and unlabeled EpiSCs. Labeled (10 nM QDs) and unlabeled cells were cultivated over a period of 10 days and counted on day 1,2 , $4,6,8$, and day 10 after labeling. Data was calculated as mean $\pm \mathrm{SE}$. from three different human donors $(n=3)$.

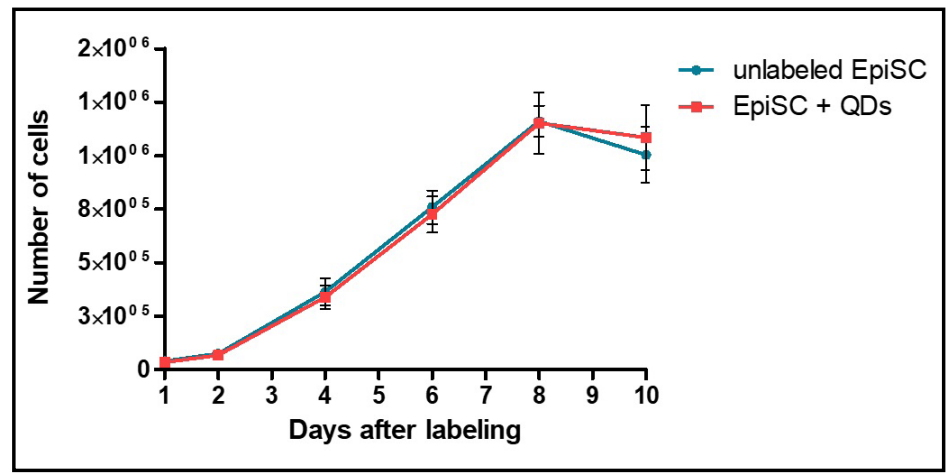

Fig. 6. Gene expression in QD labeled and unlabeled EpiSCs. The relative expression level for epidermal stem cell relevant genes was analyzed $48 \mathrm{~h}$ after QD inoculation for labeled and unlabeled cells. Normalization was performed against the reference gene $\beta$-actin. Relative gene expression was calculated as mean $\pm S E(n=3)$.

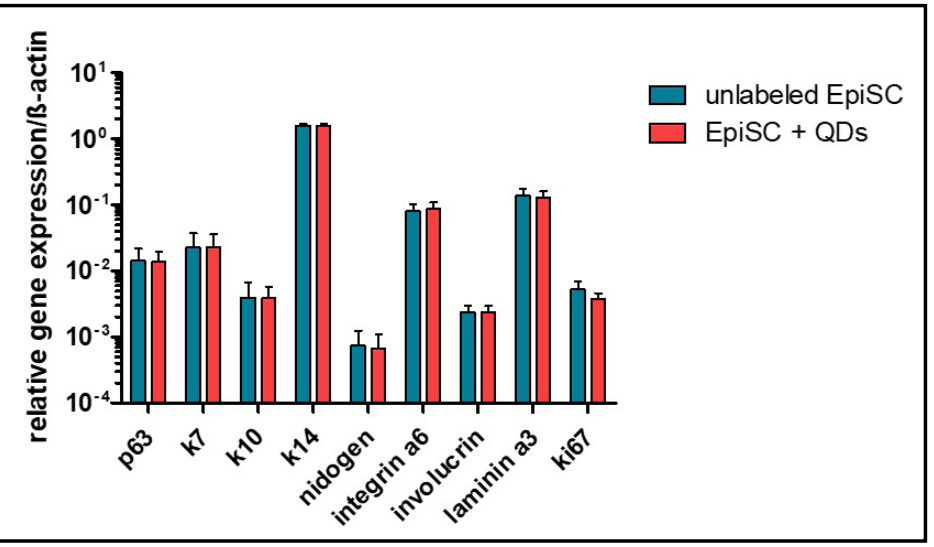




\section{Cellular Physiology}

and Biochemistry

Cell Physiol Biochem 2021;55:387-399

Quantification of immunocytochemical staining revealed also a statistically unchanged amount of marker expressing cells in QD labeled cultures in comparison to unlabeled ones (Fig. 7). All proteins analyzed were still synthesized after QD labeling.

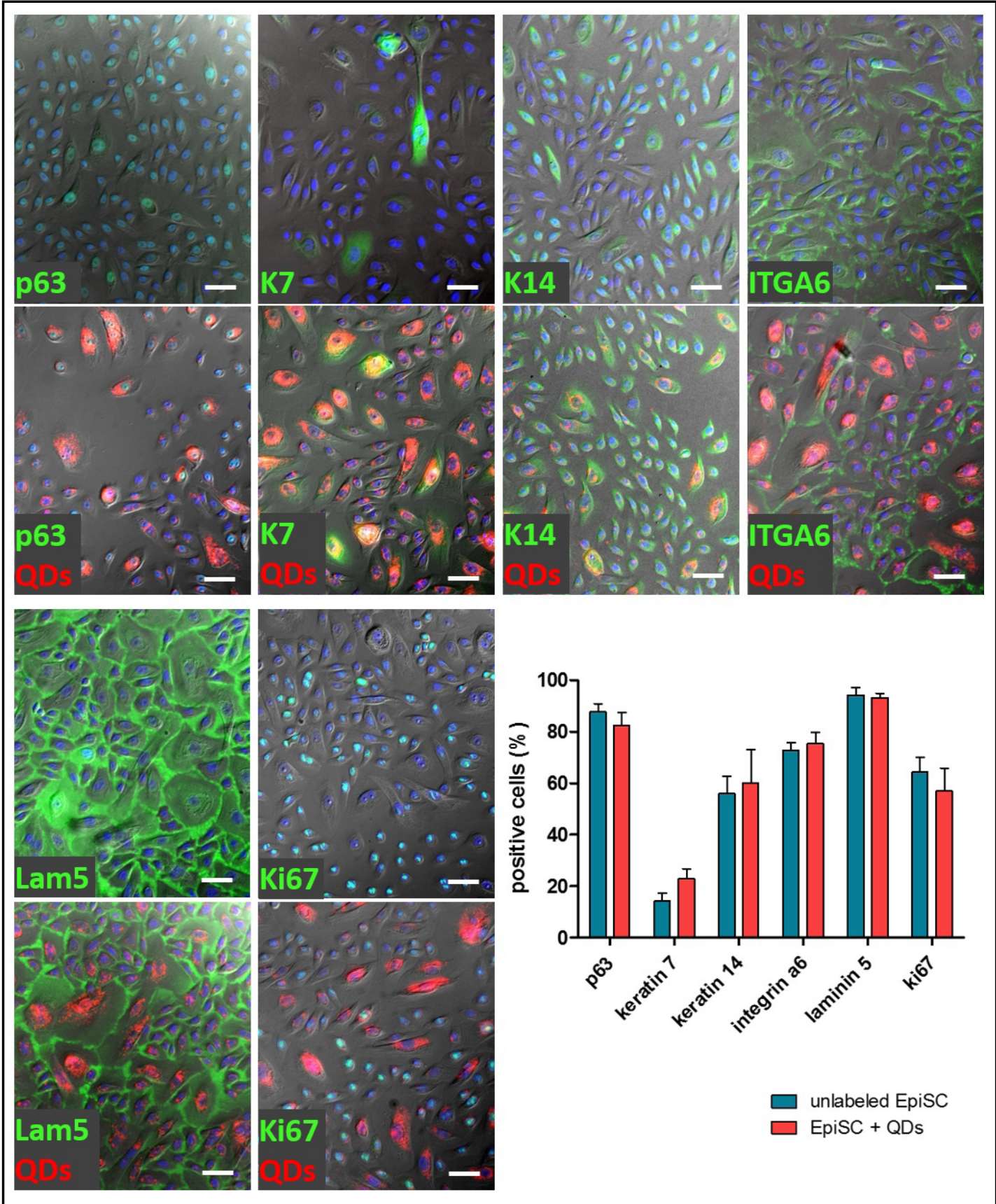

Fig. 7. Protein expression in QD labeled and unlabeled EpiSCs. Immunocytochemical staining of EpiSC specific proteins (green) and QD labeled (red) epidermal stem cells. In the diagram the amount of marker expressing cells is shown for QD labeled and unlabeled cells. Data was calculated as mean $\pm S E$. $(n=3)$; nuclei were counterstained with DAPI (blue); scale bars: $50 \mu \mathrm{m}$. 


\section{Cellular Physiology Cell Physiol Biochem 2021;55:387-399

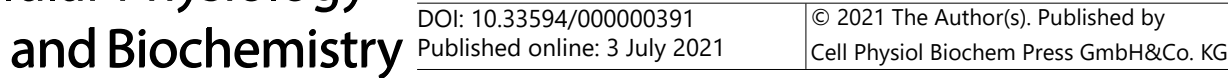 \\ Benzin et al.: Q-Dot Labeling of Skin-Derived Stem Cells}

\section{Discussion}

The substantial progress of cell-based regenerative therapies essentially depends on successful labeling techniques of the stem cells used. The major challenge for cell tracking in vitro and in vivo is long-term and non-invasive monitoring of cell migration and differentiation, as well as surveillance of the regenerative potential $[1,22,26]$. Exceptional and long-lasting fluorescence properties of quantum dot nanocrystals prone them as an excellent tool for labeling cells with the aim of tracking these cells after transplantation [12, $27,28]$. Prior to an in vivo application, we gained mandatory knowledge of the effects of QDs on the biocompatibility, proliferation and differentiation capabilities of human epithelial stem cells in vitro in this study.

Initially, the uptake and transfer of QDs in EpiSCs was characterized qualitatively and quantitatively by time lapse microscopy and FACS analysis. Thereby, we were able to show that the used QD concentration had an impact on the amount of labeled cells and also on the fluorescence intensity of the marked cells. The manufacturer recommends a QD labeling dose of $10 \mathrm{nM}$, which we also halved and doubled in order to determine the optimal concentration for our cells. At all concentrations, QDs appear to be cytocompatible with the EpiSCs and capable of labeling these cells. However, dose-dependent differences could be observed. One-half of the recommended QD dose resulted in a reduced amount of labeled cells of approximately $75 \%$ with a weak fluorescence signal. The doubling of the QD concentration, on the other hand, led to almost $100 \%$ labeling rate with a very strong fluorescence signal, which, however, hardly decreased over time. A possible reason for this stable QD labeling could be a saturation effect. The cells might have absorbed so many QDs that the measured fluorescence signal is at a maximum. Cell division and the associated thinning of the nanoparticles could therefore not be detectable in the present experimental setting.

Using $5 \mathrm{nM}$ and $10 \mathrm{nM}$ QDs, however, the labeling decreased over time. This decrease in fluorescent labeling was shown for other stem cell types like mesenchymal or embryonic stem cells before $[26,29]$ and is related to the proliferation of the cells.

With the help of time-lapse microscopy, we further analyzed the distribution of nanoparticles to daughter cells during cell division. Our observation revealed both an equal and an unequal transfer of QDs into daughter cells. This is not a specific property of EpiSCs, but has already been shown for different cell types like human mesenchymal stem cells, murine hepatocytes and human lymphocytes [29, 30, 31-33]. Since an uneven passing on of QDs on the daughter cells resulted in one cell without labeling this cell can no longer be detected. In this context, an interesting hypothesis is that this uneven transmission of QDs could be related to the asymmetric cell division of stem cells. Since stem cells have the ability to divide symmetrically and asymmetrically, the segregation of QDs in the cytoplasm along with other cell components, could be affected by these two types of division. Asymmetrical cell division would result in a labeled and an unlabeled daughter cell [34]. In this context the non-equivalent distribution of nanoparticle-loaded endosomes between daughter cells has been discussed in the literature [35]. Concerning a loss of QDs during cell culture there are discussions about an active excretion of the particles. In a study by Pi et al. [36], a quick loss of QD labeling in embryonic stem cells was observed which had been suggested to be due to the active excretion of QDs by membrane transporters. If EpiSCs have the ability to actively excrete QDs is currently unknown and has to be investigated in further analyses.

Last but not least, an optimization of the experimental procedure could help to prevent the formation of QD clusters in the labeled cells and thus achieve a more homogeneous distribution of the QDs. Sonification of the QD solution before loading the cells might be of help [37] and should be tested in novel labeling protocols. 


\section{Cellular Physiology Cell Physiol Biochem 2021;55:387-399

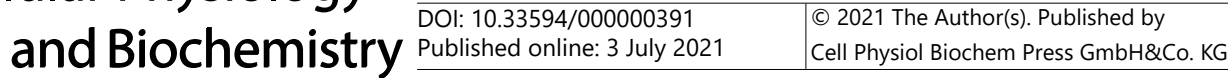 \\ Benzin et al.: Q-Dot Labeling of Skin-Derived Stem Cells}

However, we suppose that the proliferation rate of EpiSCs under self-renewal conditions in vitro is much higher than after transplantation in vivo. Thus, both effects, the decrease of QDs while cells divide and the loss of labeling due to unequal distribution during cell division, might not be as pronounced in vivo. To investigate these effects further studies will be done using an ex vivo human wound healing model based on full skin.

Here we analyzed further, if there is a long-term impact of QDs on the proliferation rate of EpiSCs. Therefore, we labeled EpiSCs and monitored their proliferation over a period of 10 days. In line with others $[26,29]$ we found no negative impact of QDs on the proliferation capability of labeled cells compared to unlabeled ones for the used concentration of $10 \mathrm{nM}$. The cells were proliferative and their growth curve displays all growth characteristic features like lag, log and stationary phase.

Obviously, for EpiSCs neither the time-lapse microscopy nor the growth curve indicates an increased cell death due to the nanoparticles. It is known that fluorescence of QDs can be lost due to degradation or irreversible structural damages $[36,38]$. In the case of a damaged CdSe core that surrounds the ZnS-shell, released cadmium ions induce toxic effects on cells [39-41]. Since no toxic effects of the nanoparticles were observed in the EpiSCs, we conclude that no significant QD degradation took place within the analyzed time period.

With regard to quality control for in vivo transplantation it is of major importance to exclude adverse effects of QDs on the specific epidermal stem cell characteristics. For this reason, we analyzed the expression of several specific markers. As Choi et al. have shown before for human pluripotent stem cell-derived cardiomyocytes [11], we were able to confirm that QDs do not affect the differentiation potential of human epidermal stem cells. All analyzed structural and functional markers were expressed at the same level for labeled and unlabeled EpiSCs. Among them, p63, one of the most important transcription factors for differentiating and proliferating epidermal stem cells [42-44] was not altered by QD labeling. Typical structural proteins of EpiSCs such as keratin 7 and keratin 14 [42-45] remained unchanged as well. Moreover, typical extracellular matrix proteins like laminin 5 and integrin $\alpha 6$ [44] were still expressed after QD labeling. Overall, applying QDs on EpiSCs did not change the expression profile for the investigated transcripts and proteins when analysed $48 \mathrm{~h}$ after labeling suggesting an unaffected differentiation potential of EpiSCs. If there might be any changes on transcriptional or translational level at very early or later timepoints (before and after $48 \mathrm{~h}$ ) had to be examined in further experiments. Future investigations should also address the question whether labeling with QDs will have any adverse effects after in vivo transplantation.

An additional challenge will be the imaging technique for the visualization of QDs in animal models [1]. Tracking the migration and destination of transplanted QD labeled cells is crucial for quality control in order to avoid harmful effects on the tissues in which they accumulate. It has been shown that QDs injected in mice accumulate in bone marrow, spleen and in the liver over a monitored period of 4 months [46].

To sum up the results of our study we have demonstrated that human epidermal stem cells could be efficiently labeled with quantum dots. Labeling with QDs had neither an influence on the cell proliferation nor on the characteristics of EpiSCs. From a technical point of view the application of QDs has several advantages. Primarily, the labeling procedure is simple and reproducible. By using a fluorescent microscope no other advanced detection equipment is needed for the further analysis of labeled cells in vitro. Furthermore, the observation of QD cell labeling down to single cell level provides a very good resolution.

The uneven transmission of QDs observed using time-lapse microscopy needs further investigation. One focus could be on the interesting question whether this unequal distribution of QDs is related to the directed distribution of cell organelles and vesicles during asymmetric cell division of epithelial stem cells. If so, that would be an exciting feature of QDs with regard to basic scientific questions on cell division of epithelial stem cells. 


\section{Cellular Physiology Cell Physiol Biochem 2021;55:387-399 \begin{tabular}{ll|l} 
and Biochemistry 10.33594/000000391 & $\begin{array}{l}\text { O } 2021 \text { The Author(s). Published by } \\
\text { Cell Physiol Biochem Press GmbH\&Co. KG }\end{array}$ \\
\cline { 2 - 3 }
\end{tabular} \\ Benzin et al.: Q-Dot Labeling of Skin-Derived Stem Cells}

\section{Conclusion}

Quantum dots are well suited for future tracking experiments in skin organ cultures or even in animal experiments. Even if the particles thin out slightly due to cell proliferation this should not be an obstacle for such ex vivo or in vivo experiments. It is likely that cells transplanted into a tissue will no longer divide so fast but rather differentiate due to the surrounding signals present in the tissue. Therefore, the QD label should be detectable in the cytoplasm of the cells over a longer period of time.

In the following, our cell based in vitro evaluation of quantum dots allows for the application of labeled human epidermal stem cells in a full-thickness human skin model $e x$ vivo. The successful tracing and monitoring of grafted cells and their differentiation potential in this model may pave the way for using quantum dots as a successful, non-invasive and efficient labeling of epidermal stem cells for in vivo applications in skin regeneration and wound healing models.

\section{Acknowledgements}

\section{Funding}

This work was founded by the European Regional Development Fund (ERDF).

\section{Statement of Ethics}

All experiments were performed in accordance with the World Medical Association Declaration of Helsinki. Utilization of human biopsies for research purposes was approved by the ethics committee of the University of Lübeck (reference number: 10-058). Involved patients gave written informed consent.

\section{Disclosure Statement}

The authors have no conflicts of interest to declare.

\section{References}

1 Villa C, Erratico S, Razini P, Fiori F, Rustichelli F, Torrente Y, Belicchi M: Stem cell tracking by nanotechnologies. Int J Mol Sci 2010;11:1070-1081.

2 Alivisatos P: The use of nanocrystals in biological detection. Nat Biotechnol 2004;22:47-52.

3 Michalet X, Pinaud FF, Bentolila LA, Tsay JM, Doose S, Li JJ, Sundaresan G, Wu AM, Gambhir SS, Weiss S: Quantum dots for live cells, in vivo imaging, and diagnostics. Science 2005;307:538-544.

4 Jaiswal JK, Goldman ER, Mattoussi H, Simon SM: Use of quantum dots for live cell imaging. Nat Methods 2004;1:73-78.

5 Das P, Ganguly S, Banerjee S, Das NC: Graphene based emergent nanolights: a short review on the synthesis, properties and application. Intermed 2019;45:3823-3853.

6 Han R, Yu M, Zheng Q, Wang L, Hong Y, Sha Y: A facile synthesis of small-sized, highly photoluminescent, and monodisperse CdSeS QD/SiO(2) for live cell imaging. Langmuir 2009;25:12250-12255.

7 Futaki S, Goto S, Suzuki T, Nakase I, Sugiura Y: Structural variety of membrane permeable peptides. Curr Protein Pept Sci 2003;4:87-96.

8 Umezawa N, Gelman MA, Haigis MC, Raines RT, Gellman SH: Translocation of a beta-peptide across cell membranes. J Am Chem Soc 2002;124:368-369.

9 Danner S, Benzin H, Vollbrandt T, Oder J, Richter A, Kruse C: Quantum dots do not alter the differentiation potential of pancreatic stem cells and are distributed randomly among daughter cells. Int J Cell Biol 2013;2013:918242. 


\section{Cellular Physiology Cell Physiol Biochem 2021;55:387-399 \begin{tabular}{ll|l} 
DOl: $10.33594 / 000000391$ & O 2021 The Author(s). Published by \\
and Biochemistry Published online: 3 July 2021 & Cell Physiol Biochen Press GmbH\&Co
\end{tabular} \\ Benzin et al.: Q-Dot Labeling of Skin-Derived Stem Cells}

10 Liu H, Tang W, Li C, Lv P, Wang Z, Liu Y, Zhang C, Bao Y, Chen H, Meng X, Song Y, Xia X, Pan F, Cui D, Shi Y: CdSe/ZnS Quantum Dots-Labeled Mesenchymal Stem Cells for Targeted Fluorescence Imaging of Pancreas Tissues and Therapy of Type 1 Diabetic Rats. Nanoscale Res Lett 2015;10:959.

11 Choi SW, Cho Y, Kim JG, Kim Y, Kim E, Chung H, Kang S: Effect of Cell Labeling on the Function of Human Pluripotent Stem Cell-Derived Cardiomyocytes. Int J Stem Cells 2020;13:287-294.

12 Grady ST, Britton L, Hinrichs K, Nixon AJ, Watts AE: Persistence of fluorescent nanoparticle-labelled bone marrow mesenchymal stem cells in vitro and after intra-articular injection. J Tissue Eng Regen Med 2019;13:191-202.

13 Kuo TR, Lee CF, Lin SJ, Dong CY, Chen CC, Tan HY: Studies of intracorneal distribution and cytotoxicity of quantum dots: risk assessment of eye exposure. Chem Res Toxicol 2011;24:253-261.

14 Hsieh SC, Wang FF, Hung SC, Chen YJ, Wang YJ: The internalized CdSe/ZnS quantum dots impair the chondrogenesis of bone marrow mesenchymal stem cells. J Biomed Mater Res B Appl Biomater 2006;79:95-101.

15 Hsieh, SC, Wang FF, Lin CS, Chen YJ, Hung SC, Wang YJ: The inhibition of osteogenesis with human bone marrow mesenchymal stem cells by CdSe/ZnS quantum dot labels. Biomaterials 2006;27:1656-1664.

16 Dekoninck S, Blanpain C: Stem cell dynamics, migration and plasticity during wound healing. Nat Cell Biol 2019;21:18-24.

17 Rzepka K, Schaarschmidt G, Nagler M, Wohlrab J: Epidermal stem cells. J Dtsch Dermatol Ges 2005;3:962973.

18 Blanpain C: Stem cells: Skin regeneration and repair. Nature 2010;464:686-687.

19 Schiestl C, Biedermann T, Braziulis E, Hartmann-Fritsch F, Böttcher-Haberzeth S, Arras M, Cesarovic N, Nicolls F, Linti C, Reichmann E, Meuli M: Skingineering II: transplantation of large-scale laboratory-grown skin analogues in a new pig model. Pediatr Surg Int 2011;27:249-254.

20 Pang C, Ibrahim A, Bulstrode NW, Ferretti P: An overview of the therapeutic potential of regenerative medicine in cutaneous wound healing. Int Wound J 2017;14:450-459.

21 Boyce ST, Lalley AL. Tissue engineering of skin and regenerative medicine for wound care. Burns Trauma. 2018;6:4.

22 Accomasso L, Gallina C, Turinetto V, Giachino C: Stem Cell Tracking with Nanoparticles for Regenerative Medicine Purposes: An Overview. Stem Cells Int 2016;2016:7920358.

23 Kim DS, Cho HJ, Choi HR, Kwon SB, Park KC: Isolation of human epidermal stem cells by adherence and the reconstruction of skin equivalents. Cell Mol Life Sci 2004;61:2774-2781.

24 Futaki S, Goto S, Suzuki T, Nakase I, Sugiura Y: Structural variety of membrane permeable peptides. Curr Protein Pept Sci 2003;4:87-96.

25 Umezawa N, Gelman MA, Haigis MC, Raines RT, Gellman SH: Translocation of a beta-peptide across cell membranes. J Am Chem Soc 2002 Jan 23;124:368-369.

26 Lin S, Xie X, Patel MR, Yang YH, Li Z, Cao F, Gheysens O, Zhang Y, Gambhir SS, Rao JH, Wu JC: Quantum dot imaging for embryonic stem cells. BMC Biotechnol 2007;7:67.

27 Ryman-Rasmussen JP, Riviere JE, Monteiro-Riviere NA: Surface coatings determine cytotoxicity and irritation potential of quantum dot nanoparticles in epidermal keratinocytes. J Invest Dermatol 2007;127:143-153.

28 Accomasso L, Gallina C, Turinetto V, Giachino C: Stem Cell Tracking with Nanoparticles for Regenerative Medicine Purposes: An Overview. Stem Cells Int 2016;2016:7920358.

29 Muller-Borer BJ, Collins MC, Gunst PR, Cascio WE, Kypson AP: Quantum dot labeling of mesenchymal stem cells. J Nanobiotechnology 2007;5:9-18.

30 Seleverstov O, Zabirnyk O, Zscharnack M, Bulavina L, Nowicki M, Heinrich JM, Yezhelyev M, Emmrich F, O’Regan R, Bader A: Quantum dots for human mesenchymal stem cells labeling. A size-dependent autophagy activation. Nano Lett 2006;6:2826-2832.

31 Hinds KA, Hill JM, Shapiro EM, Laukkanen MO, Silva AC, Combs CA, Varney TR, Balaban RS, Koretsky AP, Dunbar CE: Highly efficient endosomal labeling of progenitor and stem cells with large magnetic particles allow magnetic resonance imaging of single cells. Blood 2003;102:867-872.

32 Shapiro EM, Skrtic S, Sharer K, Hill JM, Dunbar CE, Koretsky AP: MRI detection of single particles for cellular imaging. Proc Natl Acad Sci U S A 2004;101:10901-10906. 


\section{Cellular Physiology Cell Physiol Biochem 2021;55:387-399 \begin{tabular}{ll|l}
\cline { 2 - 2 } and Bol: 10.33594/000000391 & $\begin{array}{l}\text { O 2021 The Author(s). Published by } \\
\text { Cell Physiol Biochem Press GmbH\&Co. KG }\end{array}$ \\
\hline
\end{tabular} \\ Benzin et al.: Q-Dot Labeling of Skin-Derived Stem Cells}

33 Smirnov P, Lavergne E, Gazeau F, Lewin M, Boissonnas A, Doan B, Gillet B, Combadière C, Combadière B, Clément O: In vivo cellular imaging of lymphocyte trafficking by MRI: A tumor model approach to cellbased anticancer therapy. Magn Reson Med 2006;56:498-508.

34 Lagerholm BC, Wang M, Ernst LA, Ly DH, Liu H, Bruchez MP, Waggoner AS: Multicolor Coding of Cells with Cationic Peptide Coated Quantum Dots. Nano Lett 2004;4:2019-2022.

35 Morrison SJ, Kimble J: Asymmetric and symmetric stem-cell divisions in development and cancer. Nature 2006;441:1068-1074.

36 Pi QM, Zhang, WJ, Zhou GD, Liu W, Cao Y: Degradation or excretion of quantum dots in mouse embryonic stem cells. BMC Biotechnol 2010;10:36.

37 Xu HN, Tang YY, Ouyang XK: Shear-Induced Breakup of Cellulose Nanocrystal Aggregates. Langmuir 2017;33:235-242.

38 Lee KH: Quantum dots: a quantum jump for molecular imaging? J Nucl Med 2007;48,1408-1410.

39 Parak WJ, Pellegrino T, Plank C: Labelling of cells with quantum dots. Nanotechnology 2005;16:9-25.

40 Li HC, Zhou QF, Liu W, Yan B, Zhao Y, Jiang GB: Progress in the toxicological researches for quantum dots. Sci China Ser B-Chem 2008;51:393-400.

41 Derfus AM, Chan WCW, Bhatia SN: Probing the cytotoxicity of semiconductor quantum dots. Adv Mater 2004;4:11-18.

42 Candi E, Cipollone R, Rivetti di Val Cervo P, Gonfloni S, Melino G, Knight R: p63 in epithelial development. Cell Mol Life Sci 2008;65:3126-3133.

43 Schreder A, Pierard GE, Paquet P, Reginster MA, Pierard-Franchimont C, Quatresooz P: Facing towards epidermal stem cells (Review). Int J Mol Med 2010;26:171-174.

44 Melino G, Memmi EM, Pelicci PG, Bernassola F: Maintaining epithelial stemness with p63. Sci Signal 2015;8:re9.

45 Weedon D: Weedon's Skin Pathology. Churchill Livingstone 2011, 3rd Edition, pp 248-249.

46 Ballou B, Lagerholm BC, Ernst LA, Bruchez MP, Waggoner AS: Noninvasive imaging of quantum dots in mice. Bioconjug Chem 2004;15:79-86. 